\title{
Analysis of Grid Connected Solar PV System with Distributed Per Phase Inverter with Buck Boost Control Driving Unbalanced Load
}

\author{
Arshi Jahan \\ M. Tech. Scholar \\ Department of Electrical \& Electronics Engineering \\ Oriental College of Technology \\ Bhopal, India \\ arshi_jahan@ymail.com
}

\author{
Mr. Rishabh Shukla \\ Asst. Professor \\ Department of Electrical \& Electronics Engineering \\ Oriental College of Technology \\ Bhopal, India \\ rishabhshukla002@gmail.com
}

\begin{abstract}
Small scale PV systems are mainly used in Distributed Generating systems (DG).The problem with PV DG system is for designing this system high voltage gain need to be required. In order to achieve this high gain we are choosing Grid connected PV system that is large scale Grid connected PV system In Grid connected PV system Power Electronic devices such as converters and inverters are main parts along with PV panels. In our work we have designed a solar PV system with varying irradiation in MATLAB/SIMULINK and enhance its output capacity before its integration with the grid. To design a suitable controller for per phase designed power converter such that it produces better output results than the traditional converter. The controller has to be designed along with buck boost control of DC output from the system instead of designing a whole new and separate control algorithm for inverter. It was concluded that active power output from the system from approximately $1 \mathrm{MW}$ in conventional inverter has improved to $12 \mathrm{MW}$ in the proposed scheme.
\end{abstract}

\section{I.INTRODUCTION}

Due to over population and industrialization the demand for electrical power is increasing more and more. Fossil sources also depleting day by day. In order to achieve the power demand renewable energy sources are the best alternative. Among all renewable sources Solar energy is most popular and having more abundance all over the globe and as well as pollution concern also PV system is the best alternative in renewable sources. After development of new power electronic devices it is becoming easy to establish large scale PV generating systems. There are mainly two types of generating systems in PV. One is small scale PV system and another one is large scale PV system. Small scale PV systems are mainly used in Distributed Generating systems (DG).The problem with PV DG system is for designing this system high voltage gain need to be required [1-4].

In order to achieve this high gain we are choosing Grid connected PV system that is large scale Grid connected PV system In Grid connected PV system Power Electronic devices such as converters and inverters are main parts along with PV panels. Converters are used for stepping up the voltage which is produced by PV panels. Voltage source inverters are needed for conversion of DCAC supply and for getting MPPT or stabilizing the DC voltage.

Cascaded Modular Multilevel Inverters having so many advantages like improved Waveform quality and less THD etc. For interfacing Large scale PV system with Grid the main medium we requires is this Cascaded Modular Multilevel Inverters [5]. Thus Large scale PV systems with Cascaded Modular Multilevel Inverters are facing some severe problems like mismatch of MPPT power values of each Module, Thermal gradient, dirt etc. In this entire system the input for grid is given by Cascaded Multilevel inverter which converts DC output from DCDC converter to AC supply for each phase of grid. If the output of Inverter is mismatch to the grid requirements then active power flow will get disturbs [6-7].

For example if a converter module having high active power generation then automatically that module will supply more AC supply to the grid this may cause degrade of power quality due to over modulation. In Order to overcome this problems proper control strategies are 
developing for this large scale cascaded PV systems. There are different control techniques for cascaded PV system. For DC-DC converter we will use MPPT control technique for stabilizing DC [8] voltage and for multilevel inverter we will use any of the PWM control techniques along with PI controller etc. By using this methods we can't achieve Reactive power compensation and design of $\mathrm{PV}$ system wise also some problems are there like leakage current etc.

Block Diagram for large scale Cascaded PV system is shown in Fig (1). Only single phase circuit is shown in the figure.

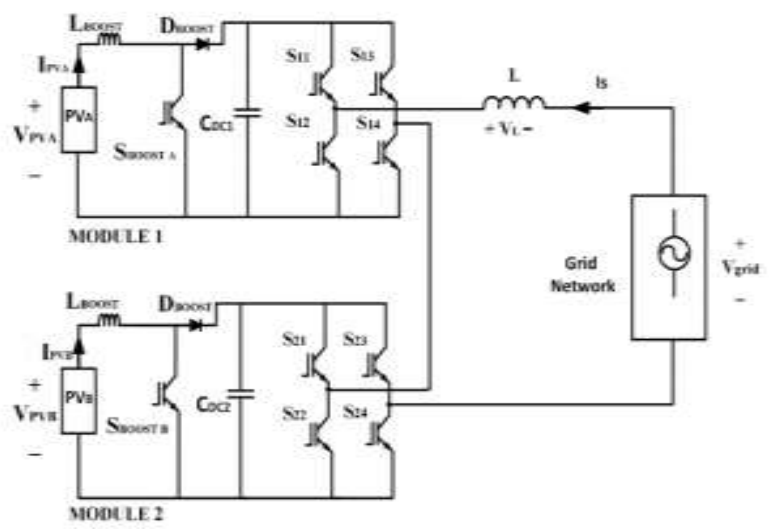

Figure 1 Block Diagram of Cascaded PV system for
one phase

\section{II.LITERATURE REVIEW}

Hee-Jun Kim et al. [1] This document describes the design of a voltage-based MPPT (Maximum Power Point Tracking) device for photovoltaic (PV) applications. Among the different MPPT methods, the constraint-based method is considered the simplest and most convenient. The main disadvantage of this method is that the photovoltaic generator is disconnected from the load to detect its open circuit voltage, which inevitably leads to a loss of power. Another disadvantage is a rapid change in radiation: too long a period between two consecutive samples, called the sampling period, is too long.

Seyed mahmoudianal. [2] the required power of the photovoltaic system (PV) is obtained by combining the photovoltaic modules in the combination of series and parallel arrangements, according to the specifications of the inverter. In general, the conversion in one phase is achieved through the serial connection of the modules to create a voltage higher than the mains voltage. The modules connected in parallel high, however, show better output power performance compared to modules connected in series with rapid changes in partial shading conditions.
SonaliSurawdhaniwar et al. [3]The need for renewable energy sources is increasing due to the acute energy crisis in today's world. India plans to generate 20 Gigawatts of solar energy by 2020, while in March 2010 we achieved less than half a Gigawatts of our potential. Solar energy is an untapped resource in a tropical country like ours. The main obstacle to the penetration and reach of photovoltaic solar systems lies in their low efficiency and high investment costs. To maximize the efficiency of a photovoltaic (PV) system, it is necessary to continuously monitor the maximum power point (MPP) of the system. Maximum Power Point Tracking (MPPT) is a technique that connects inverters, solar chargers and similar devices from a network to optimize the performance of one or more solar panels.

S. Thirumaliahet al. [4] This article focuses on the comparative study of Maximum Power Point Tracking (MPPT) algorithms with different combinations of DCDC converters. Because of the low efficiency of a photovoltaic (PV) system and non-linear V-I properties, as well as changes in irradiance and temperature, many researchers have proposed different MPPT algorithms. All the MPPT methods share the same objective of optimizing the output of the photovoltaic system by monitoring the maximum power in every operating condition. In this document, the techniques for monitoring the maximum power point (Perturb and Observe Incremental Conductance) have been introduced for photovoltaic systems to maximize the power generated.

\section{III.OBJECTIVE}

There are following objectives that are to be expected from the present work

- Designing of a solar PV system with varying irradiation in MATLAB/SIMULINK and enhance its output capacity before its integration with the grid. Also the system has to be made to drive a unbalanced load so that it is capable of handling the change in the power demand of the system.

- To design a suitable controller for the per phase designed power converter such that it produces better output results than the traditional converter.

- The controller has to be designed along with buck boost control of DC output from the system instead of designing a whole new and separate control algorithm for inverter.

- Enhance the system reliability and efficiency by integrating it with the grid via a transformer with the desired grid voltage and frequency. 


\section{IV.METHODOLOGY}

The model has been developed in MALAB/SIMULINK environment. It is a matrix / matrix matrix language with control flow instructions, functions, data structures, inputs / outputs and object-oriented programming functions. It has the following main features:

- High level language for scientific and technical computer science

- Desktop environment for exploring, designing and solving iterative problems

- Graphs to display data and tools to create customized graphs

- Applications for curve adaptation, data classification, signal analysis, control optimization and many other tasks

- Complementary toolboxes for various technical and scientific applications

- Tools to create custom applications for the user interface

- Distribution options at no cost for sharing MATLAB programs with end users

The power produced by a single module is seldom enough for commercial use, so modules are connected to form array to supply the load. The connection of the modules in an array is same as that of cells in a module. Modules can also be connected in series to get an increased voltage or in parallel to get an increased current.

The voltage and current available at the terminals of a PV device may directly feed small loads such as lighting systems and DC motors. More sophisticated applications require electronic converters to process the electricity from the PV device. These converters may be used to regulate the voltage and current at the load, to control the power flow in grid connected systems.

The proposed large scale cascaded PV system in which gives the three phase large scale Cascaded PV system in which two stages of power conversion takes place. In 1st stage power harvested from solar panel is given to DCDC converter for Boost or Buck action i.e for voltage stabilization we are using Current Fed Dual Active Bridge DC-DC converters. The modification is done with cascaded Modular Multilevel Inverters with High Voltage Insulation. DC to DC buck boost control of DC output from the system instead of designing a whole new and separate control algorithm for inverter. In this configuration no need of line frequency transformers, Inverter module is directly connected to grid without any line Frequency Transformers. This is the one of the main advantage of this model compared to conventional methods.

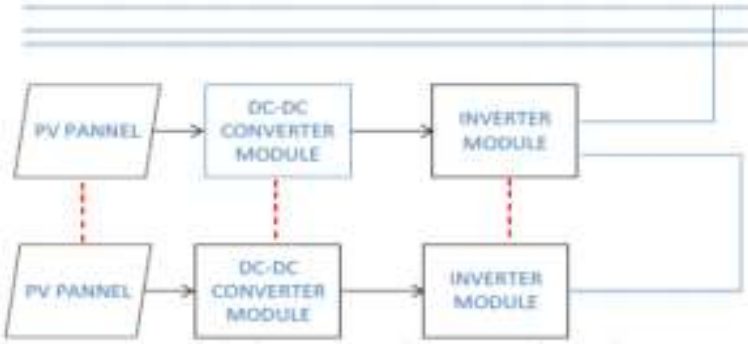

Figure 2 Proposed control scheme for the modular modeling of per phase inverter

\section{PV Module modeling:}

An ideal Solar cell is modeled by a current source in parallel with a diode in case of double exponential model i.e. Mono crystalline PV cell. The output current of PV cell depends photon current that can be also determined by load current depending upon the solar insolation during its operation equation.

PV cells have single operating point where the values of the current (I) and voltage (V) of the cell result in a maximum power output. These values correspond to a particular resistance, which is equal to V/I.

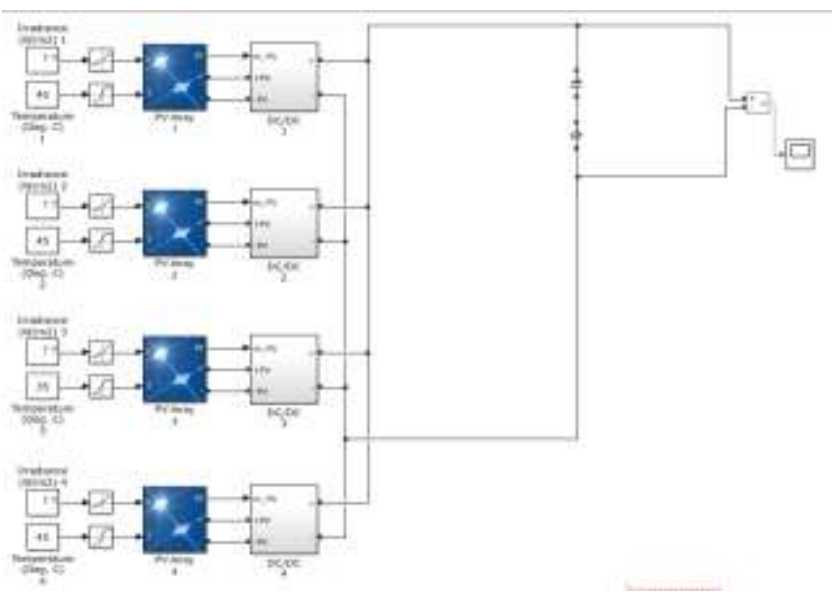

Figure 3 Modeled solar system

A cell series resistance ( Rs ) is connected in series with parallel combination of cellphotocurrent ( $\mathrm{I}_{\mathrm{ph}}$, exponential diode ( D ), and shunt resistance $\left(\mathrm{R}_{\mathrm{sh}}\right)$, I pv and $\mathrm{Vpv}$ are the cells current and voltage respectively. It can be expressed as

$I_{p v}=I_{p h}-I_{s}\left(e^{q\left(V_{p v}+I_{p v} * R_{s}\right) / n K T}-1\right)-\left(V_{p v}+I_{p v}\right.$
$\left.* R_{s}\right) / R_{s h}$

Where:

$I_{p h}$-Solar-induced current

$I_{S}$ - Diode saturation current

$q$ - Electron charge $\left(1.6 \mathrm{e}^{-19} \mathrm{C}\right)$

$K$ - Boltzmann constant $\left(1.38 \mathrm{e}^{-23} \mathrm{~J} / \mathrm{K}\right)$ 


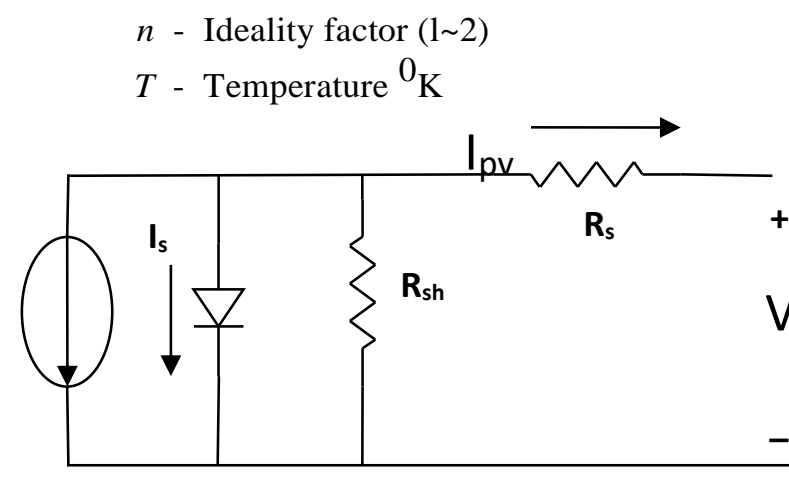

Figure 4 Equivalent circuit of solar pv cell

The solar induced current of the solar PV cell depends on the solar irradiation level and the working temperature can be expressed as:

$I_{p h}=I_{s c}-k_{i}\left(T_{c}-T_{r}\right) * \frac{I_{r}}{1000}$

Where:

$I_{S C}$ Short-circuit current of cell at STC

$K_{i}$ Cellshort-circuit current/temperature coefficient $(\mathrm{A} / \mathrm{K})$

$I_{r}$ Irradiance in $\mathrm{w} / \mathrm{m}$

$T_{c}, T_{r}$ Cell working and reference temperature at STC

A PV cell has an exponential relationship between current and voltage and the maximum power point (MPP) occur at the knee of the curve as shown in the Fig 5

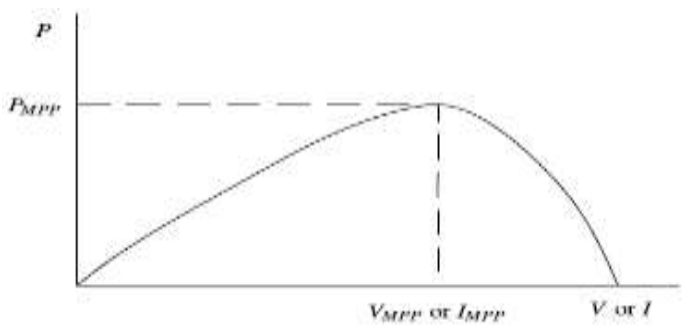

Figure 5 Characteristic PV array power curve

The $\mathrm{P} \& \mathrm{O}$ algorithm will track the maximum power to supply the DCMGs system. The assumptions for model derivation are that the ideal current source can be presented as the PVs behavior. In addition, all power converters are operated under the continuous conduction mode $(\mathrm{CCM})$ and the harmonics are also ignored.

\section{Multi Modular Cell Modeling Control}

The PV farm consists of four PV arrays at variable irradiation and variable temperature which is considered during modeling. Many factors influence PV cell temperature: module materials and construction, mounting and racking configurations, the incident irradiance (modified by shading and soiling), the wind speed at the array level, and ambient temperature, among other variables. The temperature is kept to be varying for different modules from 35 to 45 . Also irradiation is reduced at 0.5 seconds while the simulation takes place for 1 second.

ingle PV array block consist of 64 parallel strings re each string has 5 SunPower SPR-315E modules nected in series.

Each PV array is connected to a DC/DC converter (averaging) before finally providing a common DC input voltage for the inverter. Each boost is controlled by individual Maximum Power Point Trackers (MPPT). The MPPTs use the "Perturb and Observe" technique to vary the voltage across the terminals of the PV array in order get the maximum possible power. The final combination of DC output voltages from each string is taken as input DC voltage for inverter

Here in this end we design a buck boost converter control inverter for each phase which can be further integrated with the grid system.

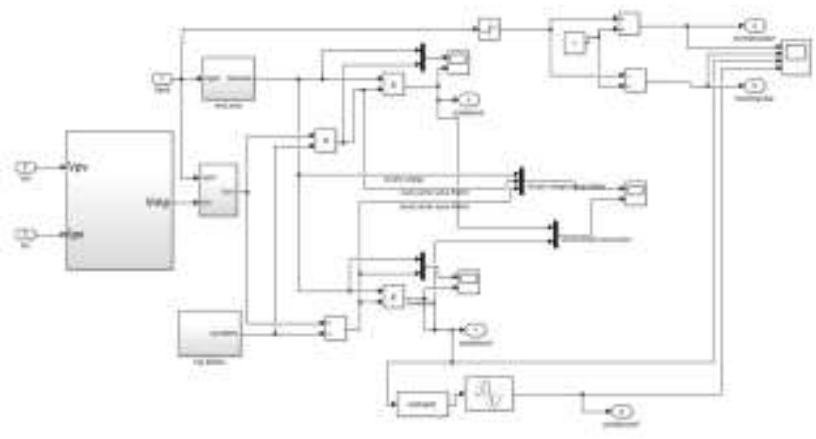

Figure 6 Combine pulse generation for per phase inverter with buck boos control in MATLAB/SIMULINK 


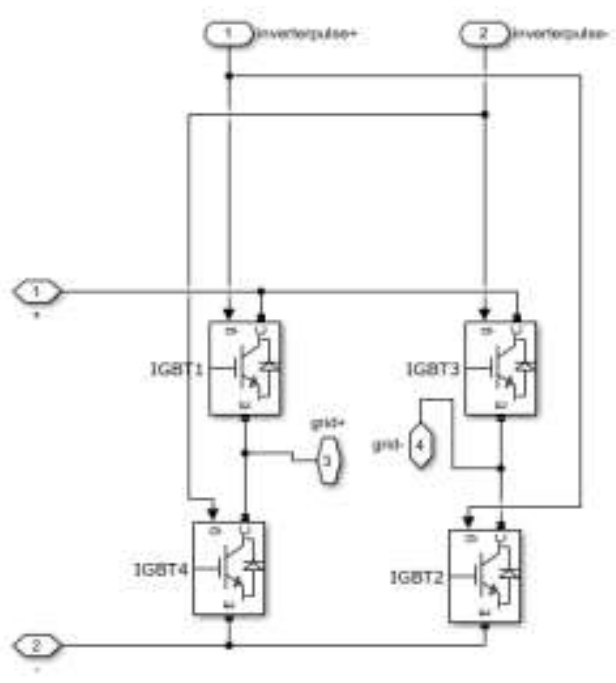

Figure 7 Per phase inverter modeling

A 400-kVA 260V/10kV three-phase coupling transformer is used to connect the converter to the grid. The grid model consists of typical $10-\mathrm{kV}$ distribution feeders and equivalent transmission system.

In the average model the boost and VSC converters are represented by equivalent voltage sources generating the $\mathrm{AC}$ voltage averaged over one cycle of the switching frequency. Such a model does not represent harmonics, but the dynamics resulting from control system and power system interaction is preserved. This model allows using much larger time steps (50 us), resulting in a much faster simulation.

\section{Unbalanced load modeling}

For stability study, to analyze the stability of a system including a power converter and constant power loads. We need to analyze the system stability from the ac side [6]. The method considers a stability study for an ac and dc distribution system connected together via a power converter

Power systems deliver energy to loads that perform a function. These loads range from household appliances to industrial machinery. Most loads expect a certain voltage and, for alternating current devices, a certain frequency and number of phases

The parameters considered for the unbalanced load. Unbalanced load makes the lines / phases to carry different current magnitudes, and sum total of these at neutral point is not zero. Load in each phase is different, carrying its own current. Neutral in this case carries the net unbalanced current. For our analysis we have considered resistive load of different magnitude for each phase. The designed power quality enhancement device is made to supply power to these unbalanced loads efficiently.

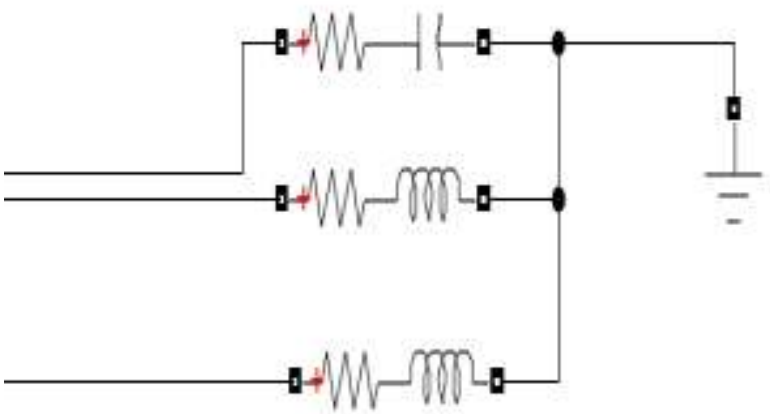

Figure 8 MATLAB/SIMULINK model of unbalanced load

The parameters and type of loads used during the simulation are being depicted in the figures above. The mixed load analysis help us to make sure that the system is being modeled efficiently for various loading conditions.

\section{V.RESULTS AND DISCUSSION}

The examination of the model has been done in MATLAB/SIMULINK condition. MATLAB consolidates a work area condition tuned for iterative investigation and design process with a programming language that communicates matrix and array science straightforwardly. It enables graphical programming to structure your framework in a simulation environment.

In this work, Solar PV system control frame works has been displayed together to upgrade the reliability of the total distributed generation [DG] framework. The work has been done to model a per phase modular inverter with the having a control of buck boost converter.

This chapter discussed the output parameters of the system in the following two cases

\section{CASE 1: Cascaded Solar PV System with Basic Inverter Control}

\section{CASE 2: Cascaded Solar PV System with per phase distributed inverter having buck boost control}

The system is being simulated for 1 second for simulation purpose in MATLAB/SIMULINK environment.

The proposed model is made to drive a unbalanced load model with minimum distortion in the voltage waveform. We have analyzed the output voltage, current and active power output from the two systems for comparative analysis. The Total harmonic distortion has also been 
calculated in voltage and current waveform from the inverter system.

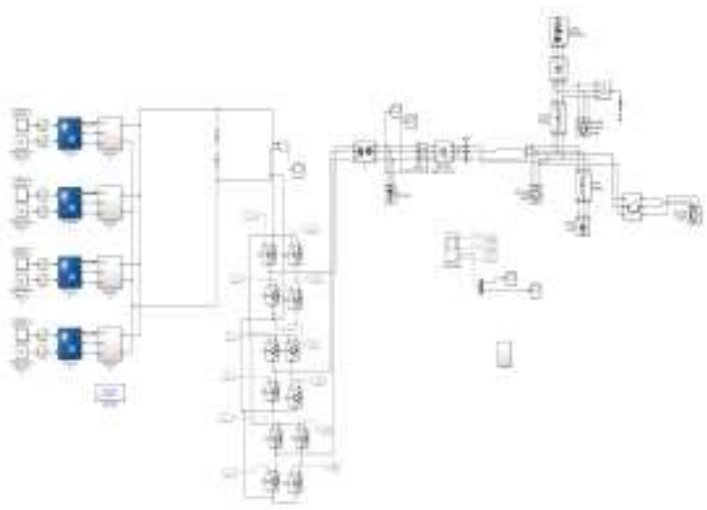

Figure 9 MATLAB/SIMULINK model of cascaded Solar PV system with basic inverter control

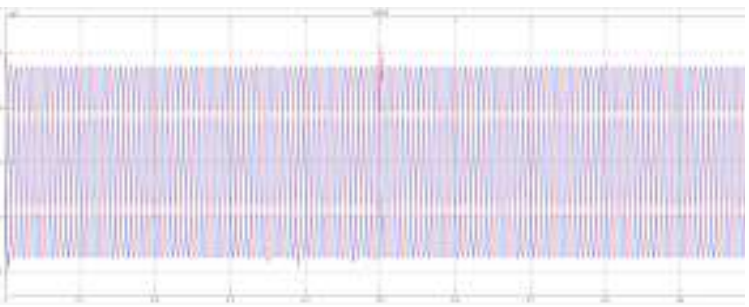

Figure 10 Voltage output from the system with basic inverter control

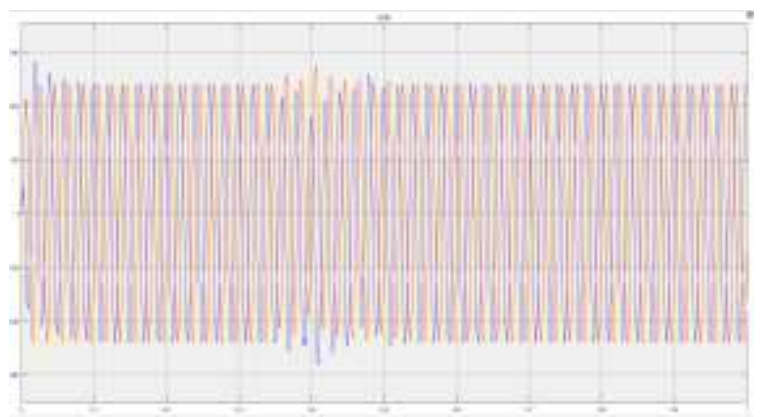

Figure 13 current output from the system with basic inverter control

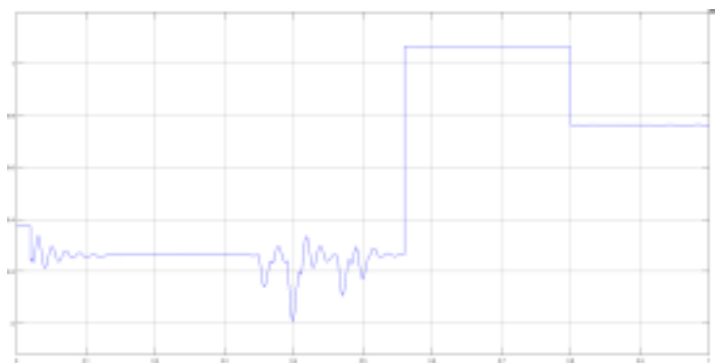

Figure 14 Active Power output from the system with basic inverter control

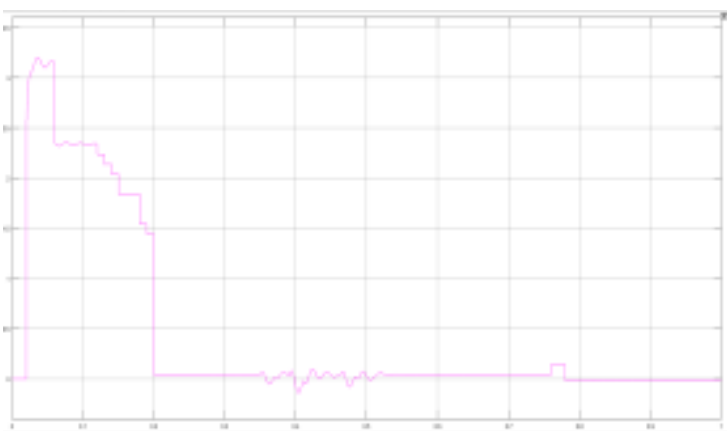

Figure 15 Reactive Power output from the system with basic inverter control

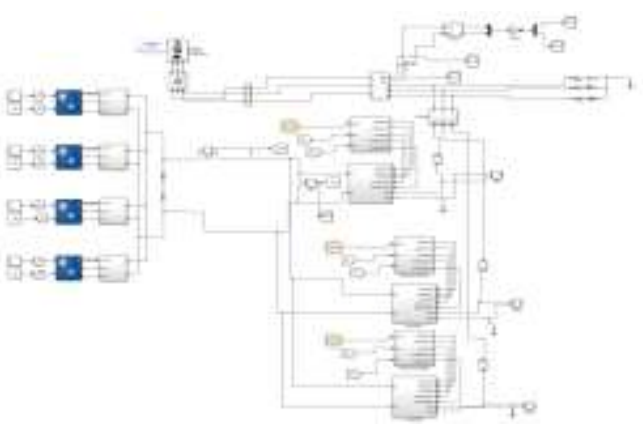

Figure 16 MATLAB Simulink Model of Solar PV system with per phase distributed inverter having buck boost control

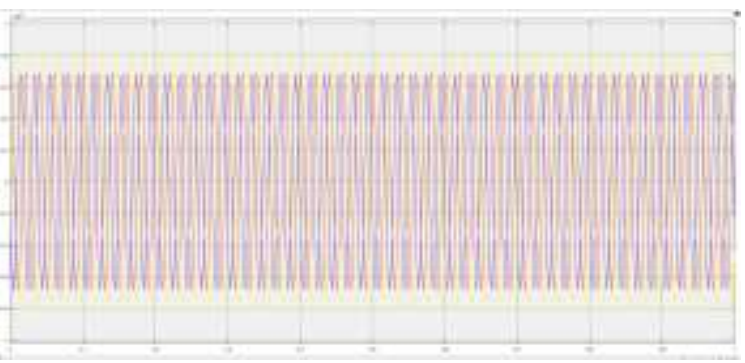

Figure 17 Voltage output from system with per phase distributed inverter having buck boost control

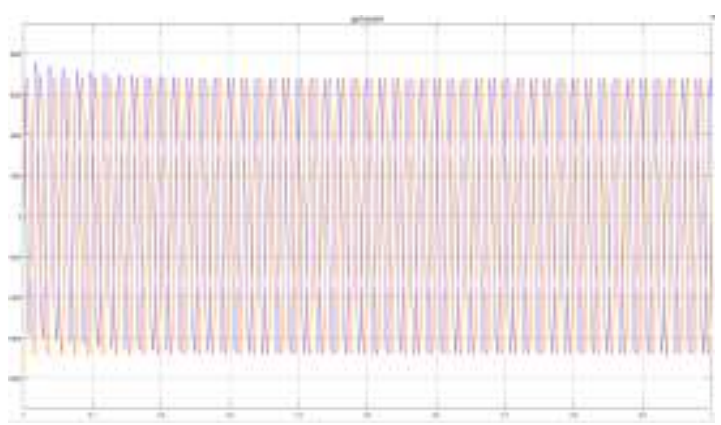

Figure 18 Current output from system with per phase distributed inverter having buck boost control 


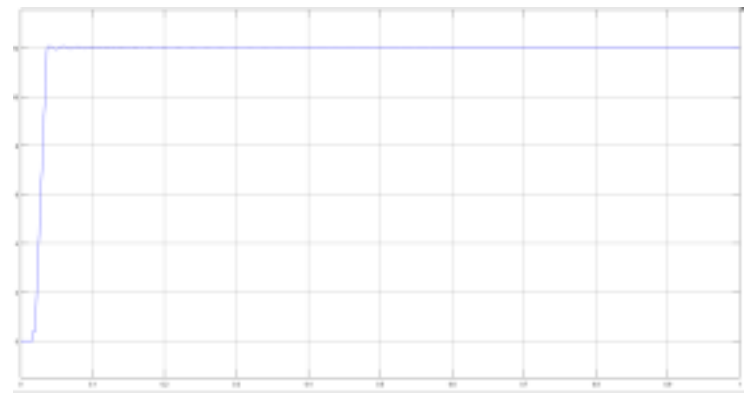

Figure 19 Active Power output from system with per phase distributed inverter having buck boost control

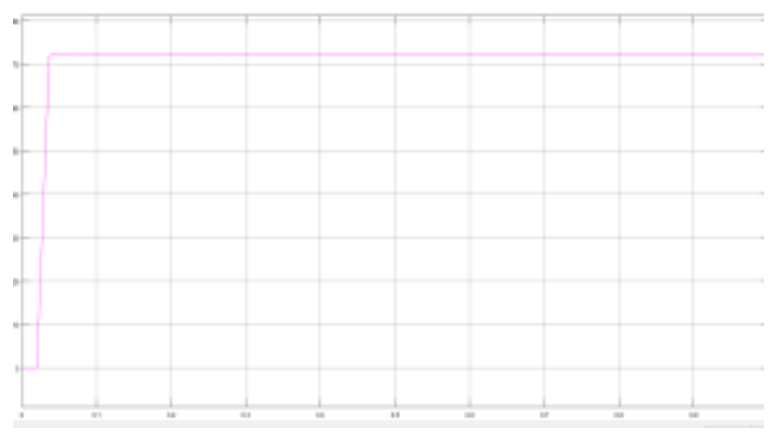

Figure 20 Reactive Power output from system with per phase distributed inverter having buck boost control

\section{VI.VALIDATION}

The comparison in the power outputs from the system with basic inverter control with the proposed system having per phase distributed inverter with buck boost control. Instead of designing whole separate algorithm for the inverter separately we have modeled our control system such that it is capable of supplying pulses o the boost converter and inverter simultaneously.

The voltage output from both the systems is maintained constant to $10 \mathrm{KV}$ attaining an improvement in the active power output. This power is then fed to the unbalanced load such that it capable of supplying power to it.

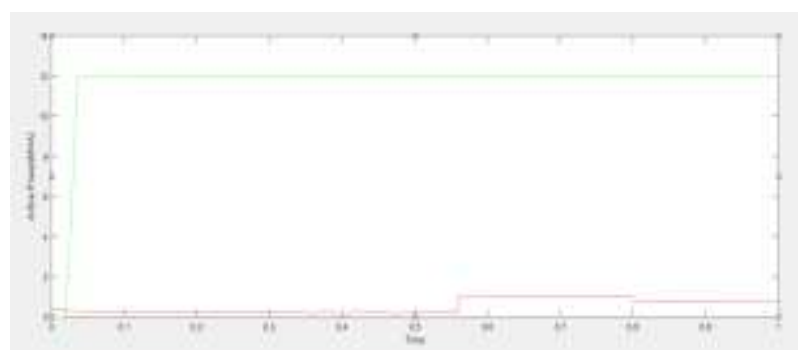

Figure 21: Comparison of active power output from the two systems
The figure 7.1 shows that the active power output from the system having basic inverter control is found to be $1 \mathrm{KW}$ and then from the proposed converter it was improved to $12 \mathrm{KW}$ output. Hence it can be concluded that the proposed inverter has reduced the complexity of the system along with an improvement in the power output.

Further the work has discussed the total harmonic distortion in the voltage and current output from the systems as well. The proposed work has witnessed a reduction in distortion level as well which concludes the efficiency of the system in all aspects.

The table below shows the enhancement parameters inferred from the two systems.

\begin{tabular}{|c|c|c|}
\hline \multicolumn{3}{|c|}{$\begin{array}{l}\text { Table : 6.1 Comparative analysis of systems with basic } \\
\text { inverter control and proposed system with per phase } \\
\text { distributed inverter having buck boost control }\end{array}$} \\
\hline Parameters & $\begin{array}{l}\text { PV system with } \\
\text { basic inverter } \\
\text { control }\end{array}$ & $\begin{array}{l}\text { Proposed system } \\
\text { with per phase } \\
\text { distributed } \\
\text { inverter having } \\
\text { buck boost control }\end{array}$ \\
\hline $\begin{array}{l}\text { Active power } \\
\text { output }\end{array}$ & $1 \mathrm{MW}$ & $12 \mathrm{MW}$ \\
\hline $\begin{array}{l}\text { THD \% in voltage } \\
\text { output }\end{array}$ & $0.09 \%$ & $0.02 \%$ \\
\hline $\begin{array}{l}\text { THD \% in current } \\
\text { output }\end{array}$ & $1.57 \%$ & $0.56 \%$ \\
\hline
\end{tabular}

\section{VII.CONCLUSION}

For on-grid solar power systems, the building is fed from both local grid and a PV array in order to cover the consumer's own power demand and decrease electricity bills. The PV panels are connected with a grid tie inverter that directly converts DC power into AC power. For micro inverters, each PV panel has its own small size inverter, which achieves optimal power conversion for each PV panel. For these inverters, if any PV panel is shaded or is not completely pointed to the sun, the total DC power is not highly affected.

This work provides a comprehensive design and implementation of three-phase Universal Bridge inverter for each phase in a PV system controlled with buck boost converter. The Inverter has been provided with proposed Modulation Technique while integrating it with the grid.

- The system designed with this as seen considerable improvement in active power output from the system from approximately $1 \mathrm{MW}$ in conventional inverter to $12 \mathrm{MW}$ in the proposed scheme.

- The voltage output is taken for fft analysis and THD is calculated. It was found that the proposed work has reduced the distortion in the output voltage being fed 
to the grid. The same is found true for current output also.

- The proposed system is also made to feed unbalanced load for the deferent phases to measure its capability of driving various loads.

- Finally the work is made efficient by integrating it with grid. The designed system is also capable of feeding reactive power to the grid when required.

\section{VIII.FUTURE SCOPE}

By connecting the super capacitor to the link of an inverter the converter can be designed for a higher voltage and a topology with transformer has to be used. Also the inverter control can be improved employing certain changes in the boost converter such that it can handle balanced and unbalanced DC voltages.

This cany be accomplished by using AI based techniques for future run. The work can be expanded to improve the quality of the network powered by renewable energy sources. By improving the signal quality of the output voltage, it can be further integrated into the network.

The modulation technique is simple and easy to implement. Using real facts can make the systems more robust and easier. With the advent of more powerful AI techniques, the computational complexity and the memory usage needs of the algorithms will decrease and more sophisticated and efficient algorithms can be implemented. It is therefore certainly true that the field of adaptive filtering will remain a long-open field for scientific research and commercial applications.

\section{REFERENCES}

[1] A. Girgis, W. B. Chang, E. B. Makram, A digital recursive measurement scheme for online tracking of harmonics, IEEE Transaction on Power Delivery, 6 (3) (1991) pp. 1153-1160.

[2] M. Bettayed, U. Qidai, Recursive estimation of power system harmonics, Electrical Power Systems Research, 47 (1998) pp. 143-152.

[3] R. Chudamani, K. Vasudevan, C. Ramalingam, Non-linear LeastSquares-based harmonic estimation algorithms for a shunt active power filter, IET Power Electronics, 2 (2) (2009) pp. 134-146.

[4] A. K. Pradhan, A. Routray, A. Basak, Power system frequency estimation using least mean square technique, IEEE Transaction on Power Delivery, 20 (3) (2005) pp. 1812-1816.

[5] B. Subudhi, P. K. Ray, S. Ghosh, Variable leaky least meansquare algorithm-based power system frequency estimation, IET, Measurement and Technology, (2012), pp.-288-297.

[6] K. Kennedy, G. Lightbody, R. Yacamini, Power system harmonic analysis using the Kalman Filter, IEEE Power Engineering Society General Meeting (2003), pp. 752-757.

[7] Vijanth S. Asirvadam,M.M. Hussam. Alhaj "Comparison of Power System Harmonic Prediction” DOI: 10.1016/j.protcy.2013.12.238

[8] M. Kelnar, RadekMartinek "Control Methods of Active Power Flters using Soft Computing Techniques” September 2015

[9] Chamandeep Kaur "power quality improvement using hybrid filter" Volume No 03, Special Issue No. 01, March 2015
[10] P. K. Dash, D. P. Swain, A. C. Liew, S. Rahman, An adaptive linear combiner for on-line tracking of power system harmonics, IEEE Transaction on Power System Harmonics, 11 (4) (1996) pp. 1730-1735. 